\title{
Coarse particulate matter associated with increased risk of emergency hospital admissions for pneumonia in Hong Kong
}

\author{
Hong Qiu, ${ }^{1}$ Lin Wei Tian, ${ }^{1,2}$ Vivian C Pun, ${ }^{1}$ Kin-fai Ho, ${ }^{1,2}$ Tze Wai Wong, ${ }^{1}$ \\ Ignatius T S Yu ${ }^{1}$
}

${ }^{1}$ The Jockey Club School of Public Health and Primary Care, The Chinese University of Hong Kong, Hong Kong Special Administrative Region, ShaTin, Hong Kong

${ }^{2}$ Shenzhen Municipal Key Laboratory for Health Risk Analysis, Shenzhen Research Institute of the Chinese University of Hong Kong, Shenzhen, China

\section{Correspondence to} Professor Lin Wei Tian, $4 / F$, The Jockey Club School of Public Health and Primary Care, Prince of Wales Hospital, The Chinese University of Hong Kong, Shatin-NT, Hong Kong Special Administrative Region, ShaTin, Hong Kong; linweit@cuhk.edu.hk

Received 16 March 2014 Revised 25 July 2014 Accepted 7 August 2014 Published Online First 27 August 2014
CrossMark

To cite: Qiu H, Tian LW, Pun VC, et al. Thorax 2014;69:1027-1033.

\section{ABSTRACT}

Background Epidemiological research on the effects of coarse particles $\left(\mathrm{PM}_{\mathrm{C}}\right.$, particulate matter between 2.5 and $10 \mu \mathrm{m}$ in aerodynamic diameter) on respiratory morbidity is sparse and inconclusive. Pneumonia is an inflammatory condition of lung caused by infections, which may be triggered and exacerbated by $\mathrm{PM}_{\mathrm{c}}$ exposure.

Aim To estimate the effect of $\mathrm{PM}_{\mathrm{c}}$ on emergency hospital admissions for pneumonia after controlling for $\mathrm{PM}_{2.5}$ and gaseous pollutants.

Method $\mathrm{PM}_{\mathrm{C}}$ concentrations were estimated by subtracting $\mathrm{PM}_{2.5}$ from $\mathrm{PM}_{10}$ measurements in each of the 10 air monitoring stations from January 2011 to December 2012 in Hong Kong and then citywide daily average concentrations of $\mathrm{PM}_{\mathrm{c}}$ were computed from the 10 stations. Generalised additive Poisson models were used to examine the relationship between $\mathrm{PM}_{\mathrm{c}}$ and daily emergency hospital admissions for pneumonia, adjusting for $\mathrm{PM}_{2.5}$ and gaseous pollutants $\left(\mathrm{NO}_{2}, \mathrm{SO}_{2}\right.$ and $\left.\mathrm{O}_{3}\right)$. Subgroup analyses by gender and age were also performed to identify the most susceptible subpopulations.

Results $\mathrm{PM}_{\mathrm{c}}$ and $\mathrm{PM}_{2.5}$ were significantly associated with emergency pneumonia hospitalisations. Every $10 \mu \mathrm{g} / \mathrm{m}^{3}$ increment of $\mathrm{PM}_{\mathrm{c}}$ in the past 4 days $\left(\operatorname{lag}_{0}-\right.$ $\left.\operatorname{lag}_{3}\right)$ was associated with a $3.33 \%(95 \% \mathrm{Cl} 1.54 \%$ to $5.15 \%$ ) increase in emergency hospitalisations for pneumonia. The effect estimates of $\mathrm{PM}_{\mathrm{c}}$ were robust to the adjustment of $\mathrm{PM}_{2.5}, \mathrm{NO}_{2}$ or $\mathrm{SO}_{2}$, but attenuated on the inclusion of $\mathrm{O}_{3}$ in the model. Women, children and older people might be more vulnerable to $\mathrm{PM}_{\mathrm{c}}$ exposure. Conclusions Short-term $\mathrm{PM}_{\mathrm{c}}$ exposure is associated with emergency hospitalisations for pneumonia in Hong Kong. Air quality regulation specifically for $\mathrm{PM}_{\mathrm{c}}$ might be considered.

\section{INTRODUCTION}

Although the effects of fine particulate matter pollution $\left(\mathrm{PM}_{2.5}\right.$, particles with an aerodynamic diameter less than $2.5 \mu \mathrm{m}$ ) associated with respiratory diseases have been well documented, ${ }^{1}$ epidemiological research on the effects of coarse particles $\left(\mathrm{PM}_{\mathrm{c}}\right.$, particulate matter between 2.5 and $10 \mu \mathrm{m}$ in aerodynamic diameter) on respiratory morbidity is sparse and inconclusive. ${ }^{2} 3$ Examining the association between $\mathrm{PM}_{\mathrm{c}}$ and health outcomes may be more difficult because coarse particles show greater spatial heterogeneity due to their larger size and shorter suspending period in the atmosphere. ${ }^{4} 5$

\section{Key messages}

What is the key question?

- Pneumonia is an inflammatory condition of the lung caused by infections; can it be triggered and exacerbated by coarse particulate matter $\left(\mathrm{PM}_{\mathrm{c}}\right)$ exposure?

\section{What is the bottom line?}

- We found an association between $\mathrm{PM}_{\mathrm{c}}$ exposure and emergency hospital admissions for pneumonia and the effect estimates of $\mathrm{PM}_{\mathrm{C}}$ were robust to the adjustment of $\mathrm{PM}_{2.5}, \mathrm{NO}_{2}$ or $\mathrm{SO}_{2}$, but were attenuated on the inclusion of $\mathrm{O}_{3}$ in the model.

\section{Why read on?}

- The reliable daily pairwise monitoring data of $\mathrm{PM}_{10}$ and $\mathrm{PM}_{2.5}$ in 10 general stations throughout Hong Kong give more accurate exposure information than data from one single station, and provide an opportunity to assess the relationship between $\mathrm{PM}_{\mathrm{c}}$ and pneumonia emergency hospitalisations.

Pneumonia is an inflammatory condition of a lobe or the whole lung caused by bacterial, viral and fungal infections. In Hong Kong, pneumonia was the second leading cause of death in 2012. An increasing trend was observed in the number of deaths and death rate since 2002. The number of deaths were 6960 , accounting for $15.9 \%$ of all registered deaths in 2012. ${ }^{6}$ Inadequate nutrition, exposure to tobacco smoke, air pollution, and not receiving immunisation may predispose people to lower respiratory tract infection. ${ }^{7}$ Indoor and outdoor air pollution have been identified as important risk factors for pneumonia. ${ }^{8-12}$ However, only a few studies have examined the association between coarse particulate matter and pneumonia ${ }^{513}$ and the results have been inconsistent. In a previous study, we used data from a single monitoring station and found the association between $\mathrm{PM}_{\mathrm{c}}$ and emergency hospitalisations for overall respiratory diseases and COPD, but failed to detect the effects of $\mathrm{PM}_{\mathrm{c}}$ on the other endpoints of respiratory diseases such as asthma, etc, ${ }^{14}$ which was probably due to the spatial heterogeneity of $\mathrm{PM}_{\mathrm{c}}$ distribution or smaller statistical power. 
Toxicological evidence supports the possibility that short-term coarse particle exposure may independently impact respiratory health by inducing inflammation that may incite or exacerbate disease. ${ }^{15}$ Pneumonia is an inflammatory condition of the lung, which may also be triggered and exacerbated by coarse particles. Hong Kong Environmental Protection Department (EPD) has begun to monitor the hourly concentrations of $\mathrm{PM}_{10}$ and $\mathrm{PM}_{2.5}$ in each of the 14 monitoring stations dispersed in the whole territory of Hong Kong since January 2011. The accurate PM concentration data provide an opportunity to assess the effects of $\mathrm{PM}_{\mathrm{c}}$ on pneumonia. In this study, we conducted a time series analysis to estimate the acute effect of $\mathrm{PM}_{\mathrm{c}}$ on emergency hospital admissions for pneumonia in Hong Kong after controlling for $\mathrm{PM}_{2.5}$ and gaseous pollutants. Subgroup analyses by gender and by age groups were also performed to identify the most susceptible subpopulations.

\section{MATERIALS AND METHODS Data collection}

Hong Kong EPD has begun to monitor the hourly concentrations of four criteria air pollutants $\left(\mathrm{PM}_{10}, \mathrm{NO}_{2}, \mathrm{O}_{3}\right.$, and $\left.\mathrm{SO}_{2}\right)$ in 14 monitoring stations dispersed in different districts of Hong Kong since 1990. Hourly concentrations of $\mathrm{PM}_{2.5}$ have been monitored in three general stations and one roadside station since 1998 and in all the 14 stations since 2011. In this study, we collected the pairwise data of $\mathrm{PM}_{10}$ and $\mathrm{PM}_{2.5}$, and gaseous pollutants in each monitoring station from January 2011 to December 2012. Three roadside stations and one station on a remote island were excluded, leaving 10 general stations to compute the citywide daily mean concentrations to represent the background air pollution level. We calculated $24 \mathrm{~h}$ mean concentrations of $\mathrm{PM}_{10}$ and $\mathrm{PM}_{2.5}$ and estimated $\mathrm{PM}_{\mathrm{c}}$ concentrations by subtracting daily mean $\mathrm{PM}_{2.5}$ from $\mathrm{PM}_{10}$ for each station. Daily average concentrations of $\mathrm{PM}_{\mathrm{c}}$ across the 10 general stations were used to represent the general population's daily exposure. We also applied similar approaches to calculate $24 \mathrm{~h}$ mean concentrations of $\mathrm{NO}_{2}, \mathrm{SO}_{2}$ and $8 \mathrm{~h}$ (10:00-18:00) mean concentration of $\mathrm{O}_{3}$ to represent the citywide pollution exposure. $^{14}$

The daily count of emergency hospital admissions for pneumonia (International Classification of Diseases, ninth revision (ICD-9): 480-486) as the principal diagnosis was obtained from the Hospital Authority Corporate Data Warehouse. Hospital Authority is the statutory body running all public hospitals in Hong Kong. The records of admission were taken from the publicly funded hospitals providing $24 \mathrm{~h}$ accident and emergency services and covering 90\% of hospital beds in Hong Kong for local residents. ${ }^{16}$ For the current study period of 2011-2012, the Hospital Authority provided us with daily counts of emergency hospital admissions aggregated over age, gender, date of admission, and principal diagnosis on discharge. We abstracted the overall daily pneumonia emergency admissions, admissions by gender and by age groups (age <15, 15-64, 65-74, $\geq 75$ years old) as the health outcomes, respectively. Daily admissions for influenza (ICD-9: 487) were used to identify influenza epidemics, which were then treated as a potential confounder in the data analysis. ${ }^{17}$ Ethics approval and consent from individual subjects were not required by our institute as we used only aggregated data but not any individualised data in this study.

The meteorological information including the daily mean temperature and relative humidity were collected from the Hong Kong Observatory.

\section{Statistical modelling}

In this time series study, generalised additive Poisson regression models were used to fit the relationship between the citywide daily $\mathrm{PM}_{\mathrm{c}}$ concentrations and the emergency pneumonia hospitalisations. We used the smoothing spline, s(.), to filter out seasonal patterns and long-term trends in daily hospitalisations, and the daily mean temperature and relative humidity. ${ }^{18}$ We also adjusted for the day of the week (DOW) and dichotomous variables such as public holidays and influenza epidemics.

We followed previous studies to select a priori model specifications and the degree of freedom (df) for the time trend and other meteorological variables. ${ }^{18} 19$ We used a df of 8/year for the time trend, a df of six for the mean temperature of the current day $\left(\mathrm{Temp}_{0}\right)$ and the previous 3 days' moving average $\left(\right.$ Temp $\left._{1-3}\right)$, and a df of three for the current day relative humidity $\left(\operatorname{Humid}_{0}\right)$. We included the DOW and public holidays (Holiday) in the model as dummy variables. ${ }^{20}$ To adjust for the potential confounding effect of an influenza epidemic on emergency hospital admissions, we entered a dummy variable for the weeks with a number of influenza hospital admissions exceeding the 75 th centile of the same year into the core model. ${ }^{17}$

Briefly, we set up a core model to remove the long-term trend, seasonal variations, and adjust for time-varying confounders as follows:

$$
\begin{aligned}
\log (\mathrm{E}(\mathrm{Y}))=\alpha & +\mathrm{s}(\mathrm{t}, \mathrm{df}=8 / \text { year } \times 2 \text { years }) \\
& +\mathrm{s}\left(\text { Temp }_{0}, \mathrm{df}=6\right)+\mathrm{s}\left(\text { Temp }_{1-3}, \mathrm{df}=6\right) \\
& +\mathrm{s}\left(\text { Humid }_{0}, \mathrm{df}=3\right) \\
& +\beta_{1} \text { DOW }+\beta_{2} \text { Holiday }+\beta_{3} \text { influenza }
\end{aligned}
$$

Here $\mathrm{E}(\mathrm{Y})$ means the expected daily counts of emergency hospital admission for pneumonia on day $\mathrm{t}$; $\mathrm{s}($.$) is the smoothing$ spline function for nonlinear variables. We examined the residuals of the core model to check whether there were discernable patterns and autocorrelation by means of residual plot and partial autocorrelation function (PACF) plot. The PACF of residuals of the core model (1) was larger than 0.1 for the first two lags, resulting in the addition of two autoregressive terms $\left(\operatorname{lag}_{1}\right.$, $\mathrm{lag}_{2}$ ) to model emergency hospital admissions for pneumonia. ${ }^{14}$ No discernible patterns and no autocorrelation in the residuals are the criteria for an adequate core model set up which is intended to remove all potential confounders in the daily variations of health outcome. The linear effects of different fractions of $\mathrm{PM}_{10}$ were then estimated for the same day and up to 6 days before the outcome (single-lag effect from $\operatorname{lag}_{0}$ to $\operatorname{lag}_{6}$ ), as previous studies have justified the linear association between the logarithm of particulate matter air pollution and respiratory morbidity. ${ }^{14}{ }^{17}$ The overall cumulative effects lasting for 0 3 days and 4-6 days were estimated by unconstrained distributed lag model (dlm03 and $\mathrm{dlm} 46) .^{21}$ Sensitivity analyses were conducted to test the effects of $\mathrm{PM}_{\mathrm{c}}$ with longer exposure windows from $\operatorname{lag}_{0}$ to $\operatorname{lag}_{13}$. The acute effects of $\mathrm{PM}_{\mathrm{c}}$ on pneumonia were examined in two-pollutant models by further adjustment for the possible confounding effects from $\mathrm{PM}_{2.5}$ and gaseous pollutants.

To identify the most susceptible subpopulation, effect differences by gender and age group were also examined by using the subgroups of pneumonia hospitalisations as the health outcomes. $^{22}$ We tested the statistical significance of differences by gender or age group through calculating $\left(\beta_{1}-\beta_{2}\right) / \sqrt{\mathrm{SE}_{1}^{2}+\mathrm{SE}_{2}^{2}}$, where $\beta_{1}$ and $\beta_{2}$ are the estimates for the two categories (eg, female and male patients), and $\mathrm{SE}_{1}$ and 
Table 1 Summary statistics of daily emergency hospital admissions for pneumonia, air pollution concentrations and weather conditions in Hong Kong 2011-2012

\begin{tabular}{|c|c|c|c|c|c|c|c|c|}
\hline \multirow[b]{2}{*}{ Variables } & \multirow[b]{2}{*}{ No of days } & \multirow[b]{2}{*}{ Mean } & \multirow[b]{2}{*}{ SD } & \multicolumn{5}{|c|}{ Centiles } \\
\hline & & & & Min & 25th & 50th & 75th & Max \\
\hline \multicolumn{9}{|c|}{ Daily emergency hospital admissions } \\
\hline Total pneumonia & 731 & 103.8 & 23.8 & 52 & 86 & 99 & 118.5 & 184 \\
\hline Female patients & 731 & 48.3 & 12.7 & 20 & 39 & 46 & 56 & 87 \\
\hline Male patients & 731 & 55.5 & 13.4 & 25 & 46 & 53 & 63 & 105 \\
\hline Age $<15$ & 731 & 11.7 & 5.1 & 2 & 8 & 11 & 14.5 & 32 \\
\hline Age $15-64$ & 731 & 14.7 & 5.3 & 3 & 11 & 14 & 17 & 40 \\
\hline Age $65-74$ & 731 & 11.1 & 3.9 & 1 & 8 & 11 & 14 & 24 \\
\hline Age $\geq 75$ & 731 & 66.3 & 16.1 & 34 & 54 & 64 & 77 & 119 \\
\hline \multicolumn{9}{|c|}{ Pollution concentration $\left(\mu \mathrm{g} / \mathrm{m}^{3}\right)$} \\
\hline $\mathrm{PM}_{10}$ & 731 & 45.44 & 23.24 & 7.56 & 25.82 & 42.95 & 61.40 & 157.35 \\
\hline $\mathrm{PM}_{2.5}$ & 731 & 30.88 & 16.79 & 4.92 & 16.70 & 28.38 & 42.80 & 85.81 \\
\hline $\mathrm{PM}_{\mathrm{c}}$ & 731 & 14.64 & 8.78 & 1.86 & 8.38 & 12.77 & 18.68 & 108.91 \\
\hline $\mathrm{NO}_{2}$ & 731 & 56.05 & 17.74 & 12.99 & 43.53 & 54.21 & 66.44 & 136.22 \\
\hline $\mathrm{O}_{3}$ & 731 & 49.42 & 32.40 & 6.12 & 24.73 & 41.71 & 68.52 & 189.76 \\
\hline $\mathrm{SO}_{2}$ & 731 & 12.42 & 6.01 & 3.27 & 8.00 & 11.15 & 15.27 & 45.32 \\
\hline \multicolumn{9}{|l|}{ Meteorology measures } \\
\hline Temperature $\left({ }^{\circ} \mathrm{C}\right)$ & 731 & 23.2 & 5.5 & 8.7 & 18.7 & 24.8 & 28.2 & 31.8 \\
\hline Relative humidity (\%) & 731 & 78.4 & 9.8 & 39.0 & 74.0 & 79.0 & 85.0 & 99.0 \\
\hline
\end{tabular}

Max., maximum; Min., minimum; $\mathrm{PM}_{2.5}$, particles with an aerodynamic diameter less than $2.5 \mu \mathrm{m}$; $\mathrm{PM}_{10}$, particles with an aerodynamic diameter less than $10 \mu \mathrm{m}$; $\mathrm{PM} \mathrm{c}_{\mathrm{c}}$ coarse particulate matter.

$\mathrm{SE}_{2}$ are their respective SEs. ${ }^{22}{ }^{23}$ An absolute value larger than 1.96 indicates a statistically significant difference at the $\alpha=0.05$ level.

The results were expressed in terms of the percentage increases (Excess Risk (\%)) in emergency pneumonia hospital admissions for $10 \mu \mathrm{g} / \mathrm{m}^{3}$ increment of $\mathrm{PM}_{\mathrm{c}}$, and their respective $95 \%$ CIs. All analyses were conducted using the 'mgcv' package ${ }^{24}$ in the statistical environment R 3.0.3 (R Development Core Team, 2014: http://www.r-project.org).

\section{RESULTS}

\section{Descriptive statistics}

We recorded a total of 75863 emergency hospital admissions for pneumonia in the study population from 1 January 2011 to 31 December 2012, accounting for $38.2 \%$ of the total respiratory diseases. The mean daily number of emergency hospital admissions for pneumonia was 104 , among which $46.5 \%$ were female patients and $53.5 \%$ were male patients. The mean daily number of admissions in the different age groups were 12,15 , 11 and 66 for age $<15,15-64,65-74$ and $\geq 75$ years, respectively (table 1).

The citywide daily mean concentrations of $\mathrm{PM}_{c}$, and $\mathrm{PM}_{2.5}$ were 14.6 and $30.9 \mu \mathrm{g} / \mathrm{m}^{3}$, with SD of 8.8 and $16.8 \mu \mathrm{g} / \mathrm{m}^{3}$, respectively. $\mathrm{PM}_{2.5}$ accounted for a substantial part of the mass concentration of $\mathrm{PM}_{10}$ with an average of $67 \%$ in Hong Kong. The daily mean concentrations of $\mathrm{NO}_{2}, \mathrm{SO}_{2}$ and $\mathrm{O}_{3}$ were 56.1, 12.4 and $49.4 \mu \mathrm{g} / \mathrm{m}^{3}$, respectively (table 1 ). Generally, $\mathrm{PM}_{10}$ was strongly correlated with $\mathrm{PM}_{2.5}$ (correlation coefficient, $\mathrm{r}=0.956)$ and $\mathrm{PM}_{\mathrm{c}}(\mathrm{r}=0.835) ; \mathrm{PM}_{2.5}$ and $\mathrm{PM}_{\mathrm{c}}$ were moderately correlated $(\mathrm{r}=0.640)$. The correlation of $\mathrm{PM}_{\mathrm{c}}$ with gaseous pollutants was low to moderate $\left(r=0.273\right.$ with $\mathrm{SO}_{2}, 0.437$ with $\mathrm{NO}_{2}$ and 0.513 with $\mathrm{O}_{3}$ ) (table 2). The time series graph showed the daily variations of emergency hospital admissions for pneumonia and air pollution concentrations during the study period (figure 1).

\section{Regression results}

Table 3 summarised the effects of the two fractions of $\mathrm{PM}_{10}$ on emergency hospital admissions for pneumonia examined in single pollutant models. We found $\mathrm{PM}_{\mathrm{c}}$ and $\mathrm{PM}_{2.5}$ to be significantly associated with pneumonia emergency hospital admissions on $\operatorname{lag}_{1}$ to $\operatorname{lag}_{4}$ days. The $0-3$-day cumulative effect (dlm03) of $\mathrm{PM}_{\mathrm{c}}$ and $\mathrm{PM}_{2.5}$ per $10 \mu \mathrm{g} / \mathrm{m}^{3}$ increment was respectively associated with a $3.33 \%(95 \%$ CI $1.54 \%$ to $5.15 \%)$ and $1.69 \%$ (95\% CI $0.68 \%$ to $2.70 \%$ ) increase in emergency hospitalisations for pneumonia. A delayed effect of $\mathrm{PM}_{2.5}$ was also found with a 4-6-day cumulative effect (dlm46) of $1.16 \%(95 \%$ CI $0.20 \%$ to $2.14 \%$ ), while the association with $\mathrm{PM}_{\mathrm{c}}$ became statistically non-significant (table 3). Association with $\mathrm{PM}_{\mathrm{c}}$ and $\mathrm{PM}_{2.5}$ became statistically non-significant on lag day and approached null on longer lag days (figure 2).

In the two-pollutant models, the effects of $\mathrm{PM}_{\mathrm{c}}$ on emergency hospital admissions for pneumonia decreased slightly but remained statistically significant on $\operatorname{lag}_{1}$ and $\operatorname{lag}_{2}$ days, and $\mathrm{d} \operatorname{lm} 03$ after adjusting for $\mathrm{PM}_{2.5}$ at the same lags. Adjustment for the gaseous pollutants showed that the effect estimates of $\mathrm{PM}_{\mathrm{c}}$ were affected by the inclusion of $\mathrm{O}_{3}$, but not $\mathrm{NO}_{2}$ or $\mathrm{SO}_{2}$ in the model (table 4). $\mathrm{O}_{3}$ had independent associations with pneumonia on $\operatorname{lag}_{1}-\operatorname{lag}_{3}$ and $\mathrm{dlm} 03$, while $\mathrm{PM}_{2.5}, \mathrm{NO}_{2}$ and $\mathrm{SO}_{2}$ only had independent effects on $\operatorname{lag}_{3}$.

Stratified analyses by gender (table 5) showed that $\mathrm{PM}_{\mathrm{c}}$ exposure exhibited slightly larger effects for female patients than for male patients, with the cumulative effect estimates ( $\mathrm{dlm} 03)$ of $4.55 \%$ (95\% CI $2.07 \%$ to $7.09 \%$ ) and $3.20 \%$ (95\% CI $0.86 \%$ to $5.59 \%$ ) increase in pneumonia hospitalisations per $10 \mu \mathrm{g} / \mathrm{m}^{3}$ increment of $\mathrm{PM}_{c}$, respectively. At the same time, $\mathrm{PM}_{\mathrm{c}}$ exposure exhibited a relatively larger effect on older people aged 65 years and older, and on children younger than 15 years old (table 5). Although it appears that female patients, children, and older people might be more vulnerable to the daily $\mathrm{PM}_{\mathrm{c}}$ exposure, the effect estimate differences between genders or among age 
Table 2 Pearson correlation coefficients between particle concentration, gaseous pollutants and weather conditions*

\begin{tabular}{|c|c|c|c|c|c|c|c|}
\hline Pollutants & $\mathrm{PM}_{10}$ & $\mathrm{PM}_{2.5}$ & $\mathrm{PM}_{\mathrm{c}}$ & $\mathrm{NO}_{2}$ & $\mathrm{O}_{3}$ & $\mathrm{SO}_{2}$ & Temperature \\
\hline $\mathrm{PM}_{10}$ & 1.000 & & & & & & \\
\hline $\mathrm{PM}_{2.5}$ & 0.956 & 1.000 & & & & & \\
\hline $\mathrm{PM}_{\mathrm{c}}$ & 0.835 & 0.640 & 1.000 & & & & \\
\hline $\mathrm{NO}_{2}$ & 0.688 & 0.734 & 0.437 & 1.000 & & & \\
\hline $\mathrm{O}_{3}$ & 0.600 & 0.559 & 0.513 & 0.463 & 1.000 & & \\
\hline $\mathrm{SO}_{2}$ & 0.458 & 0.496 & 0.273 & 0.593 & 0.312 & 1.000 & \\
\hline Temperature & -0.400 & -0.413 & -0.292 & -0.282 & 0.144 & 0.067 & 1.000 \\
\hline Relative humidity & -0.528 & -0.472 & -0.498 & -0.311 & -0.530 & -0.443 & 0.172 \\
\hline
\end{tabular}

${ }^{*}$ All correlation coefficients except that between $\mathrm{SO}_{2}$ and temperature are statistically significant $(\mathrm{p}<0.05)$.

$\mathrm{PM}_{2.5}$, particles with an aerodynamic diameter less than $2.5 \mu \mathrm{m} ; \mathrm{PM}_{10}$, particles with an aerodynamic diameter less than $10 \mu \mathrm{m} ; \mathrm{PM}_{\mathrm{c}}$, coarse particulate matter.

groups did not reach statistical significance, possibly due to the reduced study power in subgroup analyses.

\section{DISCUSSION}

This study is one of the few that have investigated the association between particulate matter pollution and pneumonia hospitalisations. We found $\mathrm{PM}_{\mathrm{c}}$ and $\mathrm{PM}_{2.5}$ were significantly associated with pneumonia emergency hospital admissions in Hong Kong. The effect estimates of $\mathrm{PM}_{\mathrm{c}}$ were robust to the adjustment of $\mathrm{PM}_{2.5}$, and gaseous pollutants $\mathrm{NO}_{2}$ or $\mathrm{SO}_{2}$, but were attenuated upon adjustment of $\mathrm{O}_{3}$. It appears that female patients, children and older people might be more vulnerable to $\mathrm{PM}_{\mathrm{c}}$ exposure.

One of our previous studies detected significant positive associations of $\mathrm{PM}_{\mathrm{c}}$ and $\mathrm{PM}_{2.5}$ with emergency hospitalisations for overall respiratory diseases and COPD, but not for other specific causes. ${ }^{14}$ One single site monitoring data was used in that study to estimate the population exposure, which may have resulted in
Figure 1 Time series graph to show the daily variation of emergency hospital admissions for pneumonia and concentrations of air pollutants. $\mathrm{PM}_{2.5}$, particles with an aerodynamic diameter less than $2.5 \mu \mathrm{m}$; $\mathrm{PM}_{\mathrm{C}}$ coarse particulate matter.

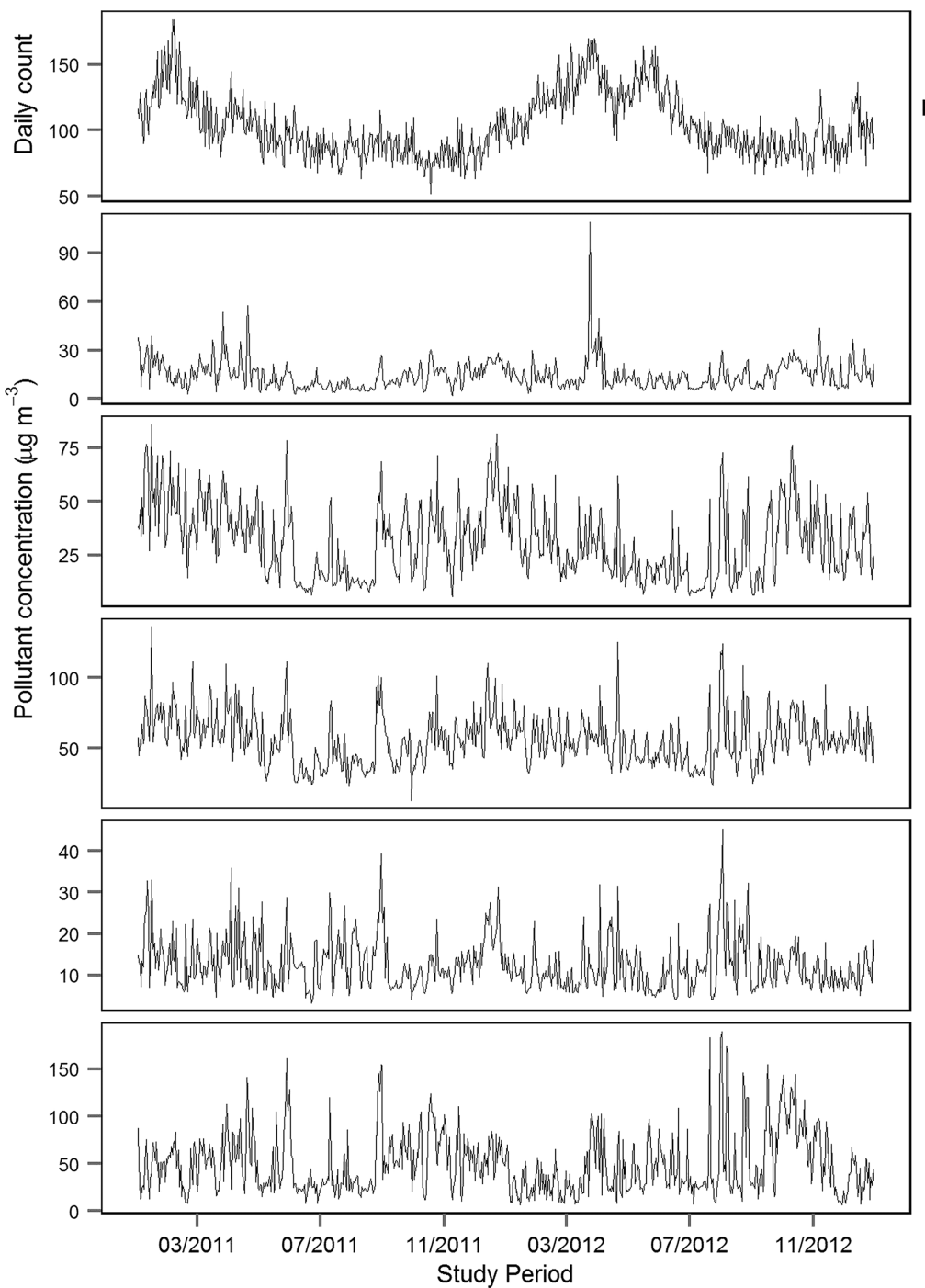

Pneumonia

PMc

PM2.5

NO2 
Table 3 Effects of different fractions of $\mathrm{PM}_{10}$ on emergency hospital admissions for pneumonia by lags in single pollutant models, 2011-2012* (ER\% (95\% Cl) for $10 \mu \mathrm{g} / \mathrm{m}^{3}$ increment of PM)

\begin{tabular}{lll}
\hline Lag days & $\mathbf{P M}_{\mathbf{C}}$ & $\mathrm{PM}_{2.5}$ \\
\hline $\mathrm{Lag}_{0}$ & $1.06(-0.22$ to 2.35$)$ & $0.68(-0.07$ to 1.43$)$ \\
$\operatorname{lag}_{1}$ & $1.57(0.42$ to 2.73$)$ & $0.72(0.00$ to 1.44$)$ \\
$\operatorname{lag}_{2}$ & $1.83(0.70$ to 2.97$)$ & $0.85(0.15$ to 1.56$)$ \\
$\operatorname{lag}_{3}$ & $1.76(0.65$ to 2.88$)$ & $1.15(0.46$ to 1.84$)$ \\
$\operatorname{lag}_{4}$ & $1.14(0.03$ to 2.26$)$ & $1.47(0.80$ to 2.14$)$ \\
$\operatorname{lag}_{5}$ & $1.07(-0.03$ to 2.19$)$ & $0.89(0.22$ to 1.57$)$ \\
$\operatorname{lag}_{6}$ & $0.82(-0.27$ to 1.93$)$ & $0.34(-0.33$ to 1.02$)$ \\
dlm03† & $3.33(1.54$ to 5.15$)$ & $1.69(0.68$ to 2.70$)$ \\
dlm46† & $0.97(-0.65$ to 2.62$)$ & $1.16(0.20$ to 2.14$)$
\end{tabular}

${ }^{*}$ Generalised additive Poisson models were used, adjusting for long-term trend, seasonality, weather factors, calendar effect and influenza epidemics.

tOverall cumulative effects of DTR lasting for 0-3 (dlm03) and 4-6 days (dlm46) were estimated by unconstrained distributed lag models. Statistically significant effect estimates are in bold.

$E R$, excess risk; $\mathrm{PM}_{2.5}$, particles with an aerodynamic diameter less than $2.5 \mu \mathrm{m}_{i}$ $\mathrm{PM}_{\mathrm{C}}$ coarse particulate matter.

$\mathrm{PM}_{\mathrm{c}}$ exposure misclassification because of the spatial variability of $\mathrm{PM}_{\mathrm{c}}{ }^{25}$ In the current study, we made use of the daily pairwise monitoring data of $\mathrm{PM}_{10}$ and $\mathrm{PM}_{2.5}$ in 10 general stations dispersed in Hong Kong to correlate the citywide daily average $\mathrm{PM}_{\mathrm{c}}$ concentrations with the daily counts of pneumonia admissions. The spatial variability of $\mathrm{PM}_{\mathrm{c}}$ concentrations was one justification for using all the $\mathrm{PM}_{\mathrm{c}}$ data from the 10 air monitors in the city. But we were not able to assign patients the monitored concentrations based on proximity to hospital or residential address because we did not have access to individual patients' information on their residential addresses or hospital names. As the average levels across the 10 monitors were more representative of the general population in the area than from a single monitor, we correlated daily counts of pneumonia with the citywide daily average concentrations of $\mathrm{PM}_{\mathrm{c}}$. We observed a significant positive association between $\mathrm{PM}_{\mathrm{c}}$ exposure and emergency hospital admissions for pneumonia. To date, few studies have examined and reported the adverse health effects of coarse particles, which focused more on the overall respiratory diseases, COPD, asthma, or overall cardiovascular diseases. ${ }^{3} 5 \quad 13 \quad 14 \quad 26-28$ Only one study conducted in Toronto, Canada reported the significant association between coarse particles and hospitalisation for respiratory infections, including pneumonia in children. ${ }^{13}$ Another Taiwan study found an acute increase in pneumonia hospitalisations on Asian dust storm event days, ${ }^{29}$ in which air pollution was predominated by high concentrations of coarse particles.
Toxicological studies proposed that the acute lung injury and an imbalance of inflammatory mediators might be causative mechanisms for the short-term association of $\mathrm{PM}_{\mathrm{c}}$ with pneumonia development. Exposure of human monocytes to particle extracts for $6 \mathrm{~h}$ at $37^{\circ} \mathrm{C}$ induced significant cytotoxicity and proinflammatory cytokines interleukin-6 and interleukin-8. ${ }^{15}$ Particulate matter is likely immuosuppressive and may undermine the normal pulmonary antimicrobial defence mechanism. $^{30}$ Happo and colleagues ${ }^{31}$ instilled particulate samples intratracheally to healthy mice either once or repeatedly on days 1,3 and 6 of the study week; they found repeated intratracheal instillation of fine and coarse particulate samples evoked enhanced pulmonary inflammation and cytotoxicity. The particulate matter induced oxidative stress and inflammation which may impair the cellular defence and immune system and increase susceptibility to bacterial pathogens. Besides the toxicological mechanisms related to its physical and chemical characteristics, $\mathrm{PM}_{\mathrm{c}}$ originated from the soil and abrasive mechanical processes may also carry biological materials such as bacteria, moulds or pollens, and are therefore likely to produce additional adverse health effects in the respiratory system. ${ }^{32}$ Our current time-series study findings on the short-term association between $\mathrm{PM}_{\mathrm{c}}$ pollution and pneumonia emergency hospitalisations were consistent with the toxicological findings of the acute adverse effects of $\mathrm{PM}_{\mathrm{c}}$.

The associations of $\mathrm{PM}_{\mathrm{c}}$ with pneumonia hospitalisations were generally robust to the adjustment of all co-pollutants, except for $\mathrm{O}_{3}$. These results may reflect the actual difference in toxicity of the corresponding pollutants themselves, but it is impossible to differentiate such factors in multi-pollutant models. The correlation coefficient between $\mathrm{PM}_{\mathrm{c}}$ and $\mathrm{O}_{3}$ $(\mathrm{r}=0.513)$ was higher than that between $\mathrm{PM}_{\mathrm{c}}$ and $\mathrm{NO}_{2}$ $(\mathrm{r}=0.437)$ or $\mathrm{PM}_{\mathrm{c}}$ and $\mathrm{SO}_{2}(\mathrm{r}=0.273)$ in Hong Kong, which might have made the effect estimates of $\mathrm{PM}_{\mathrm{c}}$ unstable upon adjustment for $\mathrm{O}_{3}$. It is likely $\mathrm{PM}_{\mathrm{c}}$ and $\mathrm{O}_{3}$ were independent players whereas the larger measurement error of $\mathrm{PM}_{\mathrm{c}}$ prevented it from remaining statistically significant, along with $\mathrm{O}_{3}$, in the two-pollutant model. ${ }^{33}$ Indeed, $\mathrm{PM}_{\mathrm{c}}$ concentrations estimated by subtracting $\mathrm{PM}_{2.5}$ from $\mathrm{PM}_{10}$ measurements were subject to double measurement error whereas directly measured ozone was subject to fewer measurement errors.

Female patients, children and elders might be more vulnerable to daily $\mathrm{PM}_{\mathrm{c}}$ exposure. Children generally breathe more rapidly than adults; they may have more exposure to air pollutants per kilogram of body weight. Older people may have a weaker immune system and higher frequency of chronic respiratory and heart diseases and thus be more vulnerable to air pollution. Female patients had substantially lower smoking prevalence compared with male patients, while the nonsmokers may be more sensitive to air pollution exposure. ${ }^{22}$
Figure 2 Sensitivity analysis to show the effects of $\mathrm{PM}_{\mathrm{c}}$ and $\mathrm{PM}_{2.5}$ on emergency hospital admissions for pneumonia with longer exposure windows from $\operatorname{lag}_{0}$ to $\operatorname{lag}_{13}$. Effects were estimated as excess risk $(95 \% \mathrm{Cl})$ per $10 \mu \mathrm{g} / \mathrm{m}^{3}$ increment of PM. $\mathrm{PM}_{2.5}$, particles with an aerodynamic diameter less than $2.5 \mu \mathrm{m} ; \mathrm{PM}_{\mathrm{C}}$ coarse particulate matter.

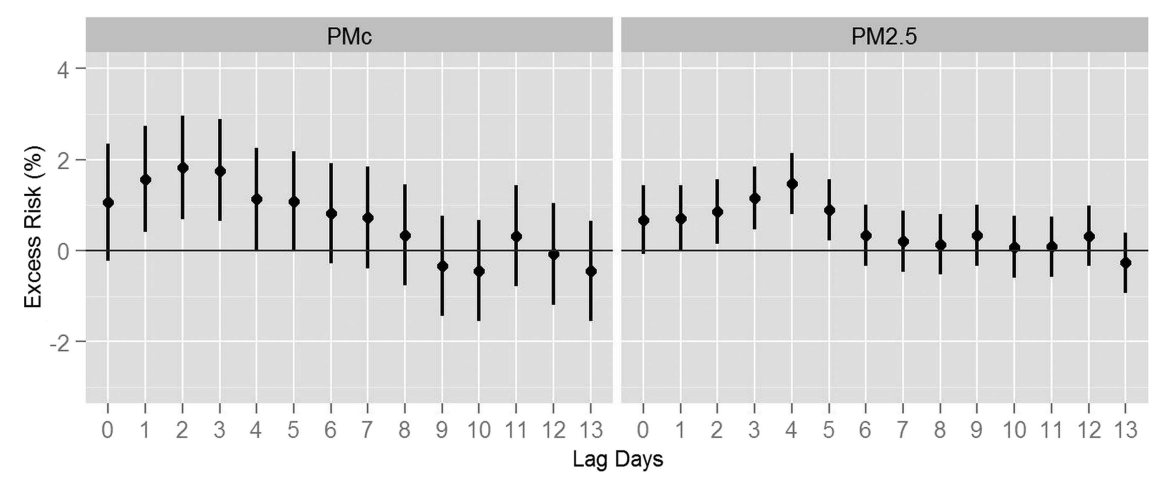


Table 4 Effects of $\mathrm{PM}_{\mathrm{c}}$ on emergency hospital admissions for pneumonia by lags in two-pollutant models, 2011-2012 (ER\% (95\% Cl) for $10 \mu \mathrm{g} / \mathrm{m}^{3}$ increment of $\mathrm{PM}_{\mathrm{c}}$ )

\begin{tabular}{|c|c|c|c|c|}
\hline Lag days & $\mathrm{PM}_{\mathrm{c}}+\mathrm{PM}_{2.5}{ }^{*}$ & $\mathrm{PM}_{\mathrm{c}}+\mathrm{NO}_{2}$ * & $\mathrm{PM}_{\mathrm{c}}+\mathrm{O}_{3} *$ & $\mathrm{PM}_{\mathrm{c}}+\mathrm{SO}_{2}{ }^{*}$ \\
\hline \multicolumn{5}{|l|}{$\mathrm{PM}_{\mathrm{c}}$} \\
\hline $\operatorname{lag}_{0}$ & $0.68(-0.73$ to 2.12$)$ & $0.99(-0.30$ to 2.30$)$ & $0.66(-0.68$ to 2.03$)$ & $1.06(-0.23$ to 2.36$)$ \\
\hline $\operatorname{lag}_{1}$ & $1.32(0.01$ to 2.65$)$ & $1.52(0.35$ to 2.70$)$ & $0.65(-0.61$ to 1.93$)$ & $1.73(0.57$ to 2.91$)$ \\
\hline $\operatorname{lag}_{2}$ & $1.52(0.20$ to 2.85$)$ & $1.71(0.56$ to 2.88$)$ & $1.08(-0.20$ to 2.37$)$ & $1.74(0.57$ to 2.91$)$ \\
\hline $\operatorname{lag}_{3}$ & $1.08(-0.22$ to 2.39$)$ & $1.41(0.26$ to 2.56$)$ & $0.92(-0.35$ to 2.21$)$ & $1.42(0.27$ to 2.58$)$ \\
\hline dlm03t & $2.43(0.41$ to 4.50$)$ & 2.90 (1.06 to 4.77$)$ & $1.38(-0.70$ to 3.51$)$ & $3.03(1.20$ to 4.89$)$ \\
\hline \multicolumn{5}{|c|}{ Second pollutant } \\
\hline $\operatorname{lag}_{0}$ & $0.51(-0.32$ to 1.34$)$ & $0.21(-0.46$ to 0.88$)$ & $0.39(-0.03$ to 0.81$)$ & $-0.03(-1.94$ to 1.91$)$ \\
\hline $\operatorname{lag}_{1}$ & $0.32(-0.50$ to 1.14$)$ & $0.15(-0.49$ to 0.79$)$ & $0.64(0.26$ to 1.02$)$ & $-1.38(-3.09$ to 0.37$)$ \\
\hline $\operatorname{lag}_{2}$ & $0.38(-0.43$ to 1.19$)$ & $0.30(-0.33$ to 0.92$)$ & $0.47(0.09$ to 0.85$)$ & 0.59 (-1.19 to 2.41$)$ \\
\hline $\operatorname{lag}_{3}$ & $0.80(0.00$ to 1.61$)$ & $0.77(0.16$ to 1.39$)$ & $0.50(0.13$ to 0.88$)$ & $1.92(0.17$ to 3.70$)$ \\
\hline dlm03t & $1.00(-0.13$ to 2.14$)$ & $0.70(-0.21$ to 1.62$)$ & $0.96(0.36$ to 1.57$)$ & $1.13(-1.64$ to 3.97$)$ \\
\hline
\end{tabular}

Consistent with previous studies, ${ }^{13} 2234$ our study suggested that special attention can be paid to the vulnerable populations such as female patients, children and older people in terms of $\mathrm{PM}_{\mathrm{c}}$ exposure.

This study had some limitations. We estimated $\mathrm{PM}_{\mathrm{c}}$ concentrations by subtracting $\mathrm{PM}_{2.5}$ from $\mathrm{PM}_{10}$ measurements so that $\mathrm{PM}_{\mathrm{c}}$ concentrations were affected by double measurement errors, which may dilute/underestimate the true associations. As in all other monitor-based time series studies, indoor air pollution and personal exposure data were not available, so outdoor monitoring data were used to represent the population exposure to ambient particles. Although a simulation study suggested that for $\mathrm{PM}_{2.5}$, ambient concentrations available from local monitoring stations might be adequate surrogates for the corresponding total personal exposures, ${ }^{35}$ the relationship between personal exposure and ambient concentrations of $\mathrm{PM}_{\mathrm{c}}$ is much less certain. Another limitation was that we could not identify the readmissions for patients with pneumonia according to the available data. It is likely that some patients, especially children and older people, were admitted to hospital more than once during the study period. Such repeated admissions could lead to a temporal dependence reflected by autocorrelation in the time series of hospitalisation counts. ${ }^{34}$
This study also had a few strengths. Although we used only 2 years of data for analysis in the current study due to the constraints of $\mathrm{PM}_{\mathrm{c}}$ data availability in multiple air monitoring stations, our daily $\mathrm{PM}_{\mathrm{c}}$ concentration time series were contiguous in the whole study period, which may facilitate the standard computation procedures and prevent the loss of study power. This was different from some earlier studies that used every third or sixth day $\mathrm{PM}_{\mathrm{c}}$ data. ${ }^{3}{ }^{13}$ We used the emergency hospital admissions for pneumonia as the health outcome. These unscheduled pneumonia hospitalisations were more likely to be community acquired and might reflect the acute effects of ambient $\mathrm{PM}_{\mathrm{c}}$ air pollution. We used air monitoring data averaged across 10 general stations dispersed in Hong Kong, which were more representative of the general population exposure than from one single monitoring station.

In conclusion, we found that $\mathrm{PM}_{\mathrm{c}}$ could play an important role in emergency hospitalisations for pneumonia in Hong Kong. The effects of $\mathrm{PM}_{\mathrm{c}}$ were robust to the adjustment for $\mathrm{PM}_{2.5}$, and gaseous pollutants $\mathrm{NO}_{2}$ or $\mathrm{SO}_{2}$, but not $\mathrm{O}_{3}$. Air quality regulation specifically for $\mathrm{PM}_{\mathrm{c}}$ might be considered.

Acknowledgements The authors thank the Hospital Authority for providing hospital admissions data, the Hong Kong Environmental Protection Department for

Table 5 Effects of $\mathrm{PM}_{\mathrm{c}}$ on emergency hospital admissions for pneumonia by gender and age groups, 2011-2012 (ER\% (95\% Cl) for $10 \mu \mathrm{g} / \mathrm{m}^{3}$ increment of $\mathrm{PM}_{\mathrm{C}}$ )

\begin{tabular}{|c|c|c|c|c|c|}
\hline & $\operatorname{lag} 0$ & lag1 & lag2 & lag3 & dlm03* \\
\hline \multicolumn{6}{|l|}{ Gender } \\
\hline Female & $1.47(-0.30$ to 3.28$)$ & $1.06(-0.53$ to 2.67$)$ & $2.34(0.79$ to 3.92$)$ & $2.92(1.40$ to 4.45$)$ & 4.55 (2.07 to 7.09$)$ \\
\hline Male & $0.95(-0.73$ to 2.65$)$ & 2.38 (0.88 to 3.91$)$ & $1.89(0.40$ to 3.40$)$ & $1.40(-0.07$ to 2.89$)$ & $3.20(0.86$ to 5.59$)$ \\
\hline \multicolumn{6}{|l|}{ Age group } \\
\hline$<15$ & $1.26(-1.96$ to 4.59$)$ & $1.73(-1.15$ to 4.70$)$ & $3.33(0.45$ to 6.29$)$ & $3.60(0.79$ to 6.49$)$ & $5.60(0.97$ to 10.44$)$ \\
\hline $15-64$ & $1.59(-1.49$ to 4.78$)$ & 0.91 ( -1.88 to 3.78$)$ & -0.02 (-2.77 to 2.81$)$ & $1.56(-1.16$ to 4.35$)$ & 2.56 (-1.69 to 6.99$)$ \\
\hline $65-74$ & $1.90(-1.61$ to 5.54$)$ & $2.44(-0.71$ to 5.69$)$ & $3.29(0.27$ to 6.39$)$ & 5.33 (2.36 to 8.39 ) & 7.33 (2.41 to 12.49 ) \\
\hline$\geq 75$ & $1.23(-0.39$ to 2.88$)$ & $2.36(0.92$ to 3.82$)$ & 2.93 (1.53 to 4.35$)$ & 2.41 (1.04 to 3.80$)$ & $4.52(2.29$ to 6.80$)$ \\
\hline
\end{tabular}

*Overall cumulative effects of pollutants lasting for $0-3$ days (dlm03) were estimated by unconstrained distributed lag models. Statistically significant effect estimates are in bold.

Differences of the effect estimates of $\mathrm{PM}_{\mathrm{c}}$ between genders or among age groups were statistically non-significant $(p>0.05)$.

$E R$, excess risk; $\mathrm{PM}_{2.5}$, particles with an aerodynamic diameter less than $2.5 \mu \mathrm{m} ; \mathrm{PM}_{\mathrm{c}}$, coarse particulate matter. 
providing air pollution monitoring data, and the Hong Kong Observatory for the temperature and humidity data.

Contributors HQ, LWT and VCP designed the study, analysed the data and drafted the manuscript; K-fH and TWW carried out data collection and interpreted the results; ITSY supervised the conduction of the study.

Competing interests The author HQ was supported by the Postdoctoral Fellowship Scheme 2013-2014 of the Faculty of Medicine, the Chinese University of Hong Kong.

Ethics approval Ethics approval was not required because only aggregated but not any individualised data were used in this study.

Provenance and peer review Not commissioned; externally peer reviewed.

\section{REFERENCES}

1 Englert N. Fine particles and human health—a review of epidemiological studies Toxicol Lett 2004:149:235-42.

2 Brunekreef $B$, Forsberg B. Epidemiological evidence of effects of coarse airborne particles on health. Eur Respir I 2005;26:309-18.

3 Peng RD, Chang HH, Bell ML, et al. Coarse particulate matter air pollution and hospital admissions for cardiovascular among Medicare patients. JAMA 2008:299:2172-9.

4 Chang HH, Peng RD, Dominici F. Estimating the acute health effects of coarse particulate matter accounting for exposure measurement error. Biostatistics 2011:12:637-52.

5 Malig BJ, Green S, Basu R, et al. Coarse particles and respiratory emergency department visits in California. Am J Epidemiol 2013;178:58-69.

6 HealthyHK Department of Health. Pneumonia. 2014. http://www.healthyhk.gov.hk/ phisweb/en/healthy_facts/disease_burden/major_causes_death/pneumonia/ (accessed 24 Jul 2014).

7 Loeb MB. Community-acquired pneumonia in older people: the need for a broader perspective. J Am Geriatr Soc 2003:51:539-43.

8 Chiu H-F, Cheng M-H, Yang C-Y. Air pollution and hospital admissions for pneumonia in a subtropical city: Taipei, Taiwan. Inhal Toxicol 2009;21:32-7.

9 Dherani M, Pope D, Mascarenhas M, et al. Indoor air pollution from unprocessed solid fuel use and pneumonia risk in children aged under five years: a systematic review and meta-analysis. Bull World Health Organ 2008;86:390-8.

10 Smith KR, McCracken JP, Weber MW, et al. Effect of reduction in household air pollution on childhood pneumonia in Guatemala (RESPIRE): a randomised controlled trial. Lancet 2011;378:1717-26.

11 Medina-Ramón M, Zanobetti A, Schwartz J. The effect of ozone and PM10 on hospital admissions for pneumonia and chronic obstructive pulmonary disease: a national multicity study. Am J Epidemiol 2006;163:579-88.

12 Neupane B, Jerrett M, Burnett RT, et al. Long-term exposure to ambient air pollution and risk of hospitalization with community-acquired pneumonia in older adults. Am J Respir Crit Care Med 2010;181:47-53.

13 Lin M, Stieb DM, Chen Y. Coarse particulate matter and hospitalization for respiratory infections in children younger than 15 years in Toronto: a case-crossover analysis. Pediatrics 2005;116:e235-40.

14 Qiu H, Yu IT-S, Tian L, et al. Effects of coarse particulate matter on emergency hospital admissions for respiratory diseases: a time-series analysis in Hong Kong Environ Health Perspect 2012:120:572-6.

15 Monn C, Becker S. Cytotoxicity and induction of proinflammatory cytokines from human monocytes exposed to fine (PM2.5) and coarse particles (PM10-2.5) in outdoor and indoor air. Toxicol Appl Pharmacol 1999;155:245-52.
16 Wong TW, Lau TS, Yu TS, et al. Air pollution and hospital admissions for respiratory and cardiovascular diseases in Hong Kong. Occup Environ Med 1999;56:679-83.

17 Wong C-M, Atkinson RW, Anderson HR, et al. A tale of two cities: effects of air pollution on hospital admissions in Hong Kong and London compared. Environ Health Perspect 2002;110:67-77.

18 Peng RD, Dominici F, Louis TA. Model choice in time series studies of air pollution and mortality. J R Stat Soc Ser A (Statistics Soc) 2006;169:179-203.

19 Qiu H, Yu IT-S, Wang X, et al. Cool and dry weather enhances the effects of air pollution on emergency IHD hospital admissions. Int I Cardiol 2013;168:500-5.

20 Schwartz J, Spix C, Touloumi G, et al. Methodological issues in studies of air pollution and daily counts of deaths or hospital admissions. I Epidemiol Community Health 1996;50(Suppl 1):S3-11.

21 Schwartz J, Samet JM, Patz JA. Hospital admissions for heart disease: the effects of temperature and humidity. Epidemiology 2004;15:755-61.

$22 \mathrm{Kan} \mathrm{H}$, London SJ, Chen G, et al. Season, sex, age, and education as modifiers of the effects of outdoor air pollution on daily mortality in Shanghai, China: The Public Health and Air Pollution in Asia (PAPA) Study. Environ Health Perspect 2008:116:1183-8.

23 Zeka A, Zanobetti A, Schwartz J. Individual-level modifiers of the effects of particulate matter on daily mortality. Am J Epidemiol 2006;163:849-59.

24 Wood SN. Generalized Additive Models: An Introduction with R. Chapman \& Hall/ CRC, 2006.

25 Lagudu URK, Raja S, Hopke PK, et al. Heterogeneity of coarse particles in an urban area. Environ Sci Technol 2011;45:3288-96.

26 Halonen Jl, Lanki T, Yli-Tuomi T, et al. Particulate air pollution and acute cardiorespiratory hospital admissions and mortality among the elderly. Epidemiology 2009;20:143-53.

27 Host S, Larrieu S, Pascal L, et al. Short-term associations between fine and coarse particles and hospital admissions for cardiorespiratory diseases in six French cities. Occup Environ Med 2008;65:544-51.

28 Tecer LH, Alagha O, Karaca F, et al. Particulate matter (PM(2.5), PM(10-2.5), and PM(10)) and children's hospital admissions for asthma and respiratory diseases: a bidirectional case-crossover study. J Toxicol Environ Health A 2008; 71:512-20.

29 Kang J-H, Keller JJ, Chen C-S, et al. Asian dust storm events are associated with an acute increase in pneumonia hospitalization. Ann Epidemiol 2012 22:257-63

30 Zelikoff JT, Schermerhorn KR, Fang K, et al. A role for associated transition metals in the immunotoxicity of inhaled ambient particulate matter. Environ Health Perspect 2002;110(Suppl):871-5

31 Happo MS, Salonen RO, Hälinen Al, et al. Inflammation and tissue damage in mouse lung by single and repeated dosing of urban air coarse and fine particles collected from six European cities. Inhal Toxicol 2010;22:402-16.

32 Almeida SM, Pio CA, Freitas MC, et al. Approaching PM(2.5) and PM(2.5-10) source apportionment by mass balance analysis, principal component analysis and particle size distribution. Sci Total Environ 2006;368:663-74.

33 Tolbert PE, Klein M, Peel JL, et al. Multipollutant modeling issues in a study of ambient air quality and emergency department visits in Atlanta. J Expo Sci Environ Epidemiol 2007;17(Suppl 2):S29-35.

34 Chen Y, Yang Q, Krewski D, et al. The effect of coarse ambient particulate matter on first, second, and overall hospital admissions for respiratory disease among the elderly. Inhal Toxicol 2005;17:649-55.

35 Schwartz J, Sarnat JA, Coull BA, et al. Effects of exposure measurement error on particle matter epidemiology: a simulation using data from a panel study in Baltimore, MD. J Expo Sci Environ Epidemiol 2007;17(Suppl 2):S2-10. 